Для реализации этих намерений имеется также объективная основа на уровне общественного сознания молодежи нашей страны. Показателем тому являются данные опроса, проведенноого нами в течение последних 3 лет, по вопросам, касающимся межкультурных взаимодействий. Опрос охватывал молодежь в возрасте от 15 до 35 лет, с объёмом выборочной совокупности 700 человек.

У нас, у членов ассоциации близкие эстетические и культурные ценности, поэтому необходимо задуматься о заполнении нашего информационного пространства продукцией общей индустрии культуры. Сегодня оно заполнено продукцией массовой культуры транснациональных компаний, в которых часто пропаганда агрессивного поведения преобладают над культуроформирующими элементами. Поэтому мы предлагаем создать на базе одного из вузов Центр информационной поддержки и обеспечения, в функции которого должно входить решение этих задач.

Уважаемые друзья! Отрадно, что среди тем, выносимых на обсуждение в данной конференции, особое место также отводится анализу туристических ресурсов стран евразийского региона. В связи с этим хочу отметить, что 2018 год в РТ объявлен годом «Развития туризма и народных ремёсел». Сегодня мы активно сотрудничаем с нашими партнёрами в рамках проблем, связанных с сохранением культурного наследия, развития инфраструктуры культурного туризма. Наша страна обладает широкими туристическими ресурсами: более 100 природных и культурных памятников. Наши взаимодействия в направлении подготовки кадров этой области помогут разработать интересные культурные технологии в туризме, изучать опыт друг друга по использованию анимации в туризме, индустрии в туризме и т. д.

Khairiddin U. Idiev, Doctor of Philosophical Sciences, Professor,

Tursunzoda Tajik State Institute of Culture and Arts Corresponding Member of Academy of Sciences of Tajikistan Republic (Dushanbe, Tajikistan) siem405@yandex.ru

\title{
INFORMATIONAL TECHNOLOGIES IN EXPANDING OF COMMONWEALTH OF INDEPENDENT STATES' CULTURAL INTERACTIONS SPACE
}

Summary. The article analysis an essence of the new trends in cultural communication between the countries of the Eurasian space that have very similar axiological systems of the public consciousness in direction of searching some information resource that is able to fill linguistically, ethnically and cultural heterogenic interstate information space with itself. The author considers close contacts between educational institutions of higher education as an essential condition for harmonic inclusion of results of interstate cultural process into cultural life space of the Commonwealth of Independent States (Azerbaijan, Armenia, Kazakhstan, Kyrgyzstan, Moldova, Russia, Tajikistan, Uzbekistan). As an evidence of the today's Tajik youth's readiness to active dialogue with peers from the CIS, the author gives some results of three-years (2015-2018) research of Tajik student youth's public opinion.

Keywords: culture, cultural interaction, a value, aesthetic values, informational space, industry of culture, cultural heritage.

\section{РАЗВИТИЕ ВОЛОНТЁРСКОГО ДВИЖЕНИЯ ЗА РУБЕЖОМ В КОНТЕКСТЕ НАЦИОНАЛЬНОЙ МОЛОДЁЖНОЙ ПОЛИТИКИ, КОНЦЕПЦИЙ СОЦИАЛЬНОГО ГОСУДАРСТВА И ГРАЖДАНСКОГО ОБЩЕСТВА}

Аннотация. В статье исследуются социально-политические факторы, способствовавшие во второй половине XX в. формированию образовательно-воспитательных направлений национальной молодёжной политики в развитых странах, созданию благоприятной досуговой среды, волонтёрского движения усилиями общественных организаций. Массовое появление таких организаций рассматривается в контексте реализации концепций социального государства и гражданского общества, различных принципов регулирования отношений между государством и обществом, применяемых в США и Великобритании, с одной стороны, в странах Западной Европы, с другой. Волонтёрство вообще и молодёжное волонтёрство в особенности развиваются за рубежом в исследуемый период как одобряемая обществом и государством идея участия молодёжи в делах местного сообщества, идея служения молодёжи обществу. 
Ключевые слова: молодёжь, национальная молодёжная политика, волонтёрское движение, общественные организации, философия холизма, социальное государство, гражданское общество, гражданское участие, принципь регулирования отношений между государством и обществом.

Молодёжь во второй половине XX века предложила миру сложные модели и образцы социализации и инкультурации, социального творчества и личностного развития в амплитуде как позитива, так и негатива. Главными особенностями молодёжи как социально-возрастной группы были признаны тенденции к группированию, созданию формальных и неформальных социокультурных групп, движений, инноваций, оформленных по закону молодёжных субкультур.

Государства развитых стран не могли не считаться с молодёжью как новым динамичным субъектом соииокультурного развития, чья социализация и инкультурация проходит в условиях постиндустриального общества. Постиндустриальное или информационное общество было осмыслено в 60-х-начале 70-х годов в работах видных западных мыслителей (Д. Белла [1], Э. Тоффлера [2] и др.) как качественно новая ступень в развитии не только Запада, но и всего человечества. Обнаружив социокультурные противоречия научно-технической революции, ученые предлагали решать мировые проблемы (экология, войны, истощение ресурсов), решая проблему качественного преобразования самого человека (антропологизм) и выдвижения в качестве ведущего сектора производства сферы культуры, (а не экономики и промышленных технологий). Стали изучаться проблемы проникновения культуры в сферы труда, политики и управления, где начала формироваться антропологическая, а также природо- и культуросообразная парадигма как революция XX века в управлении [3].

Бунт молодёжи 60-х гг. ХX в. заставил государства развитных стран обращать повышенное внимание на социально-экономическое положение, политическую и нравственную зрелость молодёжи. Проявлением позитивных общественных тенденций явился императив новой концепции устойчивого развития общества и мирового сообщества, где в 80-е годы XX века провозглашались научно обоснованные идеи качественного преобразования человека и общественной морали. Сферами этих изменений стали сферы образования и культуры с идеями стабилизации семьи и гуманизации труда, раскрывающими творческие способности человека, его инициативу.

Как показали научные исследования, на развитие идеологии ряда просоциальных альтернативных движений оказали влияние концепция Римского клуба, теория «нового качества жизни». Суть этих концепций в том, что ресурсы планеты ограничены, и новой стратегией развития объявлялась доктрина устойчивого развития с отказом от безудержного индустриализма и урбанизма, технократического рационализма, что требовало новых моделей поведения, выражающих усиление влияния индивида на общество, его связь с окружающей средой [4].
Кроме того, важнейшей тенденцией постиндустриального общества является падение статуса общественной бюрократизации и иерархизации, усиливается роль горизонтального взаимодействия между самодеятельными группами населения, непосредственно занятыми решением культурных, экономических, социальных проблем своей местности, территории, с учетом локальной специфики последних. Такие группы объединяются как временные структуры на основе не столько классовых (собственность на средства производства) и экономических (уровень доходов), сколько специфических форм социокультурной идентичности по территориальному (землячества), профессиональному (клубы ученых, менеджеров, политиков), этническому, конфессиональному признакам или на основе общения по интересам, хобби [5]. Последняя тенденция означает развитие элементов гражданского общества.

Сфера деятельности общественных организаций стран Запада обширна и разнообразна [6]. Их деятельность представляет одну из разновидностей социальной работы и направлена на организацию помощи и поддержки людям, попавшим в сложную жизненную ситуацию. Создание благоприятной досуговой среды для таких людей входит в комплекс задач общественных организаций наряду с социально-психологической, социально-экономической и социально-медицинской помощью. Многие из общественных организаций являются волонтёрскими (клубы социальной помощи, профессиональные клубы и объединений по месту жительства). Все это свидетельствует о гуманистической основе современной концепции гражданского общества за рубежом на основе философии холизма. Холизм изучает проблему культурного разнообразия на основе отказа от универсальных антиномий в создании новой модели мира, переосмысления понятия «национальной традиции», объединяя интеграционные процессы в культуре с процессами ее локализации [7].

Часть зарубежных общественных организаций занимаются разработкой своего видения национальной молодёжной политики. Целью своей деятельности они провозглашают воспитание автономной, готовой помочь, ответственной и идейной молодёжи, уделяют внимание стратегии развития внеформального воспитания. Это система организованной воспитательной деятельности, направленная на обретение жизненных навыков, развития социальных установок, ответственности, гражданственности через конкретные действия, через внешкольные общественные организации. Социально-политической средой реализации интегрированного воспитания является долгосрочная национальная государственная молодёжная политика, основанная на принципах интеграции разных общественных сил, государственных, 
партийных структур, учете национально-культурного своеобразия, заботы о менее привилегированных, и участия молодёжи в создании этой политики [8].

Обеспечением социокультурной среды, в которой разворачивается деятельность общественных организаций, политическим обеспечением деятельности молодёжных общественных организаций в развитых зарубежных странах является концепция социального государства, являющаяся характеристикой развития цивилизованного гражданского общества [9].

Становление социального государства в промышленно развитых странах началось после второй мировой войны. Для социального государства, базирующегося на принципе равноправия граждан, свойственны следующие черты: 1) забота о благосостоянии граждан; 2) создание достойных условий существования людей, равных возможностей реализации их талантов и способностей, благоприятной среды обитания; 3) утверждение нового типа социальных связей между людьми, основанных на принципах социальной справедливости, социального мира и гражданского согласия. Функции социального государства не сводятся только к поддержке социально необеспеченных слоев населения. Социальное государство несет ответственность за поддержание стабильного социального и экономического положения всех своих граждан, социального мира в обществе [10].

Практическим претворением концепции социального государства является построение гражданского общества, основная единица которого - человек-гражданин. В связи с этим актуализируется проблема формирования социально активного гражданина, ответственная деятельность и поведение которого сделают диалог общества с государством не только возможным, но и обусловленным подготовкой такого человека в аспекте создания условий для реализации его гражданского поведения с помощью концепции гражданского участия.

Краткий анализ научных подходов к трактовке концепции социального государства обусловливает также необходимость анализа понятия «гражданское общество» в зарубежной общественно-научной трактовке. К содержанию понятия «гражданское общество» в современных политологических учениях выделяется два подхода: 1) ценностно-нормативный (политико-философский) и 2) прагматический, представители которого сомневаются в необходимости использования данного понятия для характеристики политических процессов $[11 ; 12 ; 13]$.

Но возможно использовать понятие «гражданское общество» как форс-идею (П. Бурдье) для выдвижения нормативных идеалов и целей развития человеческих обществ, поскольку (по М. Веберу) гражданское общество характеризуется социальностью (акцентом на отношениях между людьми, а не между людьми и вещами); автономностью от государства; гражданственностью (цивилизованностью), т. е. умением так или иначе учитывать интересы других и общества в целом, действовать в правовых рамках; добровольностью участия, включая политическое участие, и преобладанием горизонтальных связей над вертикальными [14].

Модифицированным современным вариантом концепции благотворительности является конщепциия гражданского участия. Ее суть в том, что человек в демократическом обществе помимо прав имеет свои обязанности, например, такие, как добровольная работа на благо общества. В этом случае гражданин рассматривается как человек, знающий и активно отстаивающий свои права, при этом он имеет право не только принимать участие в управлении государством, но и обязан это делать [15].

Процесс регулирования отношений между государством и обществом, влияние общества на социализацию человека осуществляется за рубежом на основе двух принципов: 1) субсидиарности; 2) социального контроля, используемых в практической реализации концепции социального государства и гражданского участия.

На основании принципа субсидиарности местное сообщество берет на себя городские заботы в пределах своей территории. Городские власти и государство отвечают за решение более масштабных проблем. Поэтому участие в решении проблем местного сообщества (района, улицы и т. д.) не только право, но и святая обязанность гражданина, реализуемая на основе добровольчества (волонтёрства). Добровольчество как модель гражданского поведения, участия, социальной активности реализуется за рубежом (например, в Германии) как добровольная самоорганизация граждан для решения собственных социальных проблем.

Принцип социального контроля П. Бергера порождает иной вариант социальных отношений и социализации гражданина. Этот принцип эффективен в плане социального воспроизводства и обеспечения прогнозируемого, ожидаемого поведения со стороны людей (целенаправленного поведения по М. Веберу). При этом государство несет минимальные расходы по воспроизводству и контролю, делегируя полномочия местному сообществу, накопление ответственности идет «снизу» (на уровне семьи и частной жизни), государство при этом удерживает полный контроль над ситуацией. Эта модель принята в Англии и США, где добровольчество также является механизмом воспитания законопослушного и социально активного (на своем уровне) гражданина. Волонтёрство в англоязычных странах широко распространено среди домохозяек (семья и частная жизнь), в корпорациях (профессиональный уровень), имеет свое нормативно-правовое обеспечение (политико-юридическая система), более (в Англии) или менее (в США) политизировано [16]. Особое внимание в университетах США уделяется волонтёрской деятельности. Она помогает: 1) экономить бюджет в социальной сфере, сфере здравоохранения, спорта, туризма, культурно- 
зрелищной сфере; 2) формирует не только гражданские качества, но и качества профессиональные, т. е. востребованные в будущей профессии студента [17].

Институт добровольчества в данном случае помогает социальным структурам, выполняющим воспитательные функции и поддерживающим порядок в обществе. Все это способствует формированию на основе гражданских добровольческих инициатив добровольческого движения, имеющего внушительные масштабы и организационные формы институционализации. Об этом подробно изложено в монографии автора статьи [18].

\section{Список литературы}

1. Белл Д. Грядущее постиндустриальное общество. Москва, 1973. 284 с.

2. Тоффлер Э. Футурошок, или шок перед будущим. Москва, 1973. 284 с.

3. Основы современного сочиального управления: теория и методология. Москва, 2000. $271 \mathrm{c.}$

4. Краткий словарь по сочииологии. Москва, 1989. 479 с. Из содерж.: Молодёжи социальные проблемы. С. 164-166; Социология молодёжи. С. 353354.

5. Ерасов Б. С. Социальная культурология. Москва, 1994. Ч. 2. 240 с.

6. Оленина Г.В., Харина А. С. Формирование ценностей патриотизма и гражданственности молодёжи в деятельности российских и зарубежных движений // Учёные записки (Алтайская государственная академия культуры). 2017. № 2. С. 80-83.

7. Современная западная социология. Москва, 1990. 432 c.
8. Воспитание молодёжи: заявление на заре XXI века. Начиональная молодёжная политика: точка зрения молодёэных организаций внеформального воспитания. URL: https://www.youthworker.by/ images/_library/mezhdunarodnyj_dokument_po_vospitaniyu. $\operatorname{pdf}(31.03 .2016)$.

9. Словарь-справочник по сочиальной работе. Москва, 2002. 424 с. Из содерж.: Социальное государство. С. 62-65.

10. Политология. Москва, 2003. 176 с.

11. Гражданское общество: истоки и современность. Санкт-Петербург, 2003. 256 с.

12. Ильин М. В. Слова и смыслы. Опыт описания ключевых политических понятий. Москва, 1997. $432 \mathrm{c}$.

13. Коэн Дж. Л. Гражданское общество и политическая теория. Москва, 2003. 784 с.

14. Резник Ю. М. Гражданское общество как феномен человеческой цивилизации. Москва, 1993. Ч. $1.167 \mathrm{c}$.

15. Корнилович В. А. Социальный механизм воспитания в условиях трансформации российского общества (технология «Импульс»). Барнаул, 2002. $149 \mathrm{c}$.

16. Очман $M$. Как работать с волонтёрами. Алматы, 1999. 68 с.

17. Пальцева О. П. Социально-культурная работа за рубежом. Тамбов, 2007. $320 \mathrm{c.}$

18. Оленина Г. В. Социально-культурное проектирование и продвижение гражданских инициатив молодёжи: история, теория, методология, практика. Барнаул, 2012. 311 с

Galina V. Olenina, Doctor of Pedagogical Science, Professor Altai State Institute of Culture (Barnaul, Russia) ustlama@mail.ru

\section{VOLUNTEER MOVEMENT ABROAD IN CONTEXT OF STATE YOUTH POLICY, SOCIAL STATE AND CIVIL SOCIETY THEORIES}

Summary. The newness of the article is determined by the need to explain: what social, cultural and political factors have an influence on volunteer movement development that involves various strata of the population including the youth in the United Sates and other western advanced countries? Why, in general, foreign human sciences get started to study dynamically the youth's problems? On what theoretical basis and practical principles volunteer movement on the $20^{\text {th }}$ century had been fixed in a state youth policy? Was it in accordance with trends of development of a social state and a civil society?

The author answering these questions bases on the foreign scientists' key idea: for the first time, science of the 1960s had recognized the youth as an active actor of social and cultural development - the youth that was socialized and enculturated in a post-industrial society filled with paradoxes and difficulties. This had been shown in the western youth's mass civil unrests of the 1960s and also, in the appearance, uncontrolled extension of the youth's subcultures in the 1970s and the 1980s which were mostly not positive in its nature.

The theory of civic participation, the youth's public service in way of volunteering was the sought idea. It has been spreading in the field of family, professional relations and private life of various population groups (including the youth's learning activity) by efforts of numerous of public non-profit organizations that were ruled a state youth policy.

The article argues the European countries and the United States regard the volunteer phenomenon as an economically advantageous thing, and in addition, it helps to the government structures to fulfill its disciplinary function.

The author of the article concludes: volunteer movement abroad became a popular model of a civic 
behavior; today's volunteer movement in general and youth's volunteer movement in particular develop abroad as socially and politically approved idea of the youth's participation in local community's life, the idea of the youth's public service.

\section{References}

1. Bell D. Grjadushhee postindustrial'noe obshhestvo [The Coming of Post-Industrial Society]. Moscow, 1973. 284 p. [In Russ.].

2. Toffler A. Futuroshok, ili shok pered budushhim [Future Shock]. Moscow, 1973. 284 p. [In Russ.].

3. Osbovy sovremennogo social'nogo upravlenija: teorija i metodologija [Basics of Today's Social Management: Theory and Methodology]. Moscow, 2000. 271 p. [In Russ.].

4. Kratkij slovar' po sociologii [Shorter Dictionary On Sociology]. Moscow, 1989. 479 p. Fr. the cont.: Social'nyj problemy molodjozhi [Youth's Social Problems]. Pp. 164-166; Sociologija molodjozhi [Sociology of Youth]. Pp. 353-354. [In Russ.].

5. Erasov B.S. Social'naya kul'turologiya [Social Cultural Studies]. Moscow, 1994. Pt. 2. 240 p. [In Russ.].

6. Olenina G. V., Kharina A.S. Formirovanie cennostej patriotizma i grazhdanstvennosti molodyozhi v deyatel'nosti rossijskih i zarubezhnyh dvizhenij [The Youth's Patriotic and Civic Conscience Values Forming in Russian and Abroad Movements] // Uchyonye zapiski (Altajskaya gosudarstvennaya akademiya kul'tury) [Scientific Notes (Altai State Academy of Culture and Arts)]. 2017. No. 2. Pp. 80-83. [In Russ.].

7. Sovremennaya zapadnaya sociologiya [Modern Western Sociology]. Moscow, 1990. 432 p. [In Russ.].

8. Vospitanie molodyozhi: zayavlenie na zare XXI veka. Nacional'naya molodyozhnaya politika: tochka zreniya molodyozhnyh organizacij vneformal'nogo vospitaniya [The Upbringing of the Youth: Message at The Beginning of the $21^{\text {st }}$ century. The State Youth Policy: The Youth Non-Formal Education Organizations'
Point of View]. URL: https://www.youthworker.by/ images/_library/mezhdunarodnyj_dokument_po_vospitaniyu.pdf (31.03.2016). [In Russ.].

9. Slovar'-spravochnik po social'noj rabote [Dictionary and Guide On Social Work]. Moscow, 2002. 424 p. Fr. the Cont.: Social'noe gosudarstvo [Social State]. Pp. 62-65. [In Russ.].

10. Politilogia [Political Science]. Moscow, 2003. 176 p. [In Russ.].

11. Grazhdanskoe obshchestvo: istoki i sovremennost' [Civic Society: Origins and Modernity]. Saint Petersburg, 2003. 256 p. [In Russ.].

12. Ilyn M. V. Slova i smysly. Opyt opisaniya klyuchevyh politicheskih ponyatij [Words and Essences. The Experience of Key Political Concepts Portraying]. Moscow, 1997. 432 p. [In Russ.].

13. Cohen J. L. Grazhdanskoe obshchestvo i politicheskaya teoriya [Civic Society and Political Theory]. Moscow, 2003.784 p. [In Russ.].

14. Reznik Yu. M. Grazhdanskoe obshchestvo kak fenomen chelovecheskoj civilizacii [Civic Society as The Phenomenon of The Human Civilization]. Moscow, 1993. Pt. 1. 167 p. [In Russ.].

15. Kornilovich $V$. A. Social'nyj mekhanizm vospitaniya $\mathrm{v}$ usloviyah transformacii rossijskogo obshchestva (tekhnologiya «Impul's») [Social Mechanism of Upbringing in Changing Russian Society ("Impulse" Technology)]. Barnaul, 2002. 149 p. [In Russ.].

16. Ochman M. Kak rabotat's volontyorami [How to Lead the Volunteers]. Almaty, 1999. 68 p. [In Russ.].

17. Pal'ceva O.P. Social'no-kul'turnaya rabota za rubezhom [Social and Cultural Activity Abroad]. Tambov, 2007. 320 p. [In Russ.].

18. Olenina G. V. Social'no-kul'turnoe proektirovanie $\mathrm{i}$ prodvizhenie grazhdanskih iniciativ molodyozhi: istoriya, teoriya, metodologiya, praktika [Social and Cultural Projection and The Youth's Civic Initiatives Promoting: History, Theory, Methodology, Practice]. Barnaul, 2012. 311 p. [In Russ.].

Н. В. Серёгин, доктор педагогических наук, профессор Алтайский государственный институт культуры (Барнаул, Россия) sereginnv@yandex.ru

\section{ХУДОЖЕСТВЕННОЕ ОБРАЗОВАНИЕ В СОВРЕМЕННОМ МИРЕ}

Аннотация. В статье обоснована психолого-дидактическая парадигма оптимальной организации художественного образования. Выявлены инновационные технологии, построенные на полидисциплинарной основе, имеющие личностно-ценностную направленность проектирования нового типа развивающих художественнообразовательных сред, требующие усовершенствованных средств, методов обучения и учебных пособий нового поколения. Психодидактическая система художественной деятельности углубляет развитие конкретных областей психики в образовательном процессе и закрепляет их чувственной сферой. Рассматриваются современные подходы к построению образовательно-воспитательного процесса, ориентирующиеся на необходимость интеллектуального и нравственного развития подрастающего поколения, целенаправленное формирование критического и творческого мышления. 